\title{
Perception of static magnetic field by humans: a review
}

\section{Nikita Chernetsov ${ }^{1,2}$, Inna Nikishena ${ }^{3,4}$, Natalia Zavarzina ${ }^{4}$, and Olga Kulbach 4}

'Sechenov Institute of Evolutionary Physiology and Biochemistry, Russian Academy of Sciences, pr. Toreza, 44, Saint Petersburg, 194223, Russian Federation

${ }^{2}$ Zoological Institute, Russian Academy of Sciences,

Universitetskaya nab., 1, Saint Petersburg, 199034, Russian Federation

${ }^{3} \mathrm{~N}$. P. Bekhtereva Institute of the Human Brain, Russian Academy of Sciences,

ul. Akademika Pavlova, 12a, Saint Petersburg, 197376, Russian Federation

${ }^{4}$ St. Petersburg State Pediatric Medical University,

Litovskaya ul., 2, Saint Petersburg, 194100, Russian Federation

Address correspondence and requests for materials to Nikita Chernetsov, nikita.chernetsov@gmail.com

\section{Abstract}

We review the scientific data available on the ability of humans to perceive static magnetic fields with intensities comparable to the intensity of the natural geomagnetic field. It is currently assumed that birds have at least two independent magnetoreceptory systems. Various authors have reported the existence of the sensory ability to perceive the Earth's magnetic field and to use it for spatial orientation in different species of mammals. The question of whether this ability exists in humans has been raised repeatedly. During the past 40 years, serious scholarly titles have published the results of behavioral studies on humans' ability to perform homing to their home range by magnetic cues, of the ability to point towards a certain magnetic compass direction, and claims of magnetic modulation of the ability to discriminate weak light flashes. Several research groups have tried to find out whether brain bioelectric activity responds to changes in the stationary magnetic field. Cortical activation following changes in the static magnetic field, which suggested transduction of the changes in the Earth's magnetic field into neural responses, was found by analyzing eventrelated synchronization/desynchronization. However, no behavioral manifestation for the putative magnetoreception in humans is evident. All attempts to detect behavioral responses to magnetic field changes in humans have been less than convincing.

Keywords: magnetic field, magnetoreception, sensory system, humans

\section{Introduction}

Humans are known to lack the sensory ability to perceive the magnetic field, at least the conscious ability. This fact was one of the reasons why all suggestions and reports of magnetoreception in animals have been met with skepticism by many researchers. The suggestion that migrating birds may use geomagnetic information for orientation during their seasonal movements has been forwarded as early as mid-19th century (von Middendorff, 1855). In the 1960s the ability to orient by Earth's magnetic field was shown in songbirds by behavioral experiments (Wiltschko, 1968; Wiltschko and Wiltschko, 1972). The first reports met skepticism that bordered on accusations of pseudoscience. The well-known student of avian migration and orientation Victor Dolnik wrote that 'all studies of non-celestial (i.e., magnetic - Authors) orientation in birds are not more successful than the studies of human telepathy' (Dolnik, 1973). An important contribution leading to the general acceptance of magnetoreception studies was, first, publication of the results of avian orientation studies in Science (Wiltschko and Wiltschko, 1972) and second, the joint publication by Roswitha and 
Wolfgang Wiltschko and their U.S. colleagues from the group of Stephen Emlen, who was initially very cautious towards the reports of a magnetic compass in birds, but was subsequently persuaded by the robust experimental evidence (Emlen et al., 1976).

It is currently assumed that birds possess at least two independent magnetoreceptory systems with different biophysical bases, localized in different parts of the body and with a different neuroanatomical basis (Mouritsen et al., 2016; Mouritsen, 2018). One system is believed to be localized in the retina and may be based on light-dependent biradical chemical reactions with cryptochrome as the sensory molecule (Hore and Mouritsen, 2016). Information from this magnetoreceptor is processed in the specialized part of visual Wulst, the so-called cluster N. There are reasons to believe that this vision-based magnetoreceptor enables perception of compass information which is necessary for longrange orientation of migratory birds (Mouritsen, 2018). The second magnetoreceptory system is probably based on the magnetic properties of iron oxide(s) (biogenic magnetite), is located somewhere in the upper beak, with the exact location and ultrastructure of receptors unknown, and is innervated by the ophthalmic branch of the trigeminal nerve. This system may participate in spatial representation and form the basis of a kind of a map, or less sophisticated beacons, based on the regular variation of the geomagnetic field (Heyers et al., 2010, Pakhomov et al., 2018; Kobylkov et al., 2020).

Many authors have reported the use of the magnetic compass and alignment of the body axis along magnetic lines in animals other than birds, including the following mammals: rodents (Deutschlander et al., 2003; Phillips et al., 2013; Malewski et al., 2018), bats (Holland et al., 2006), ungulates (Begall et al., 2008), canids (Benediktová et al., 2020) and many others, reviewed by Begall et al., 2014. Naturally, the question of the existence of a similar sensory modality in humans has been raised.

In this contribution, we review the studies on the ability of humans to perceive the static magnetic field with parameters comparable to those of the geomagnetic field in a relatively natural behavioral context. The total intensity of the geomagnetic field varies from ca. $60 \mu \mathrm{T}$ near the magnetic poles to ca. $30 \mu \mathrm{T}$ near the magnetic equator, locally down to $24 \mu \mathrm{T}$ (Skiles, 1985). In the southern hemisphere the magnetic lines are directed upwards, near the magnetic south pole (which does not coincide with the geographic South Pole) vertically upwards, and at lower magnetic latitudes under an increasingly obtuse angle. At the magnetic equator, the geomagnetic lines run parallel to the surface - this is actually the definition of the magnetic equator, which does not coincide with the geographic equator. In the northern hemisphere, the magnetic lines are directed downwards, and on the magnetic North Pole vertically downwards (Skiles, 1985).
The impact of strong magnetic fields on humans is used in clinical practice and is known as transcranial magnetic stimulation (TMS; Schlaepfer and Kosel, 2004). A magnetic coil is placed on the scalp above certain brain zones, and an electric pulse generator generates a changing electric current within the coil that induces a magnetic field with an intensity ca. $1.5-3 \mathrm{~T}$, which is stronger than the geomagnetic field by five orders of magnitude. The physiological bases underlying modulations induced by TMS and rTMS have not been elucidated clearly. The alternating magnetic field penetrates the skull by $1.5-3 \mathrm{~cm}$, depending on frequency, and induces the electric current; it depolarizes superficial axons and activates networks in the cortex. Transmission of the signal through synapses to excitatory and inhibitory neurons can cause responses of various types (Huerat and Volpe, 2009; Bortoletto et al., 2015). The neurophysiological effect of TMS is governed by localization, intensity and duration of stimulation.

Application of TMS in research and clinical practice is increasing. TMS is used in treatment and rehabilitation neurological and psychiatric diseases, e.g., epilepsy, migraines, Parkinson's disease, strokes, muscular dystonia, speech disorders, etc. (Evstigneev and Kisten', 2013; Belopasova et al., 2015; Chervyakov et al., 2015; Charnukha et al., 2016; Misra et al., 2017), and also mental conditions (Hoffman et al., 2000; Perera et al., 2016). It should, however, be emphasized that the biological effect of TMS is based not on perception of the magnetic field and processing of the signal, but on the direct electric stimulation of cortical neurons. Therefore, we do not include TMS in this review, but rather focus on the studies whose authors attempted to study sensory perception of the static magnetic field by humans. This topic is much more debatable.

Before discussing the arguments in favor of the existence of a special sensory system in humans that perceives changes in magnetic fields, it is necessary to define the concept of "sensory system". The perception of any external information begins with the effect of the stimulus on the receptor cells. The receptors are characterized by specificity, i.e., they demonstrate a response to signals of a certain modality, to which they were adapted in the course of evolution. This position is reflected in Johannes Müller's concept of "specific sense energies", according to which sensation is determined by a sensory organ, not by a sensory signal (Norrsell et al., 1999). The information from the receptors reaches the projection fields of the cerebral cortex, where sensation is formed, which is understood as the mental reflection of individual properties of objects under the direct action of the stimulus on the receptors (Gippenreyter et al., 2002).

The neurophysiological basis of sensation is analysis, i.e., the perception of qualitative and quantitative signs of a signal. The result of the analyzers' work is the transformation of these signs into certain sensory quali- 
ties, which in turn are the mental characteristics of the same signal (Schmidt, 1981). Sensations allow us to determine the modality, duration, intensity and spatial localization of the stimulus. The emergence of sensations is the result of the work of analyzers (sensory systems) (Schmidt, 1981; Kulbach and Zavarzina, 2019).

Humans and non-human animals perceive by far not every environmental signal. Analyzers formed in humans in the course of evolution provide a sensory representation of the world that is typical of humans. Obviously, to test the hypothesis that humans have the ability to perceive changes in magnetic fields, a whole array of studies should be carried out. It is necessary not only to find the corresponding receptors, but also to determine the involvement of the cortical areas of the brain in the formation of sensation. It can be identified by recording a certain behavioral response to the perceived stimulus. A possible direction is electrophysiological studies, using registration of changes in the electroencephalogram parameters in response to changes in the magnetic field parameters.

\section{Behavioral studies in humans}

Homing is the ability of an animal to return to the individual home range after translocation at distances that obviously exceed the size of the familiar area. Homing experiments are a widely accepted and long-established method of studying animal navigation (Rüppel, 1944; Chernetsov et al., 2004; Thorup et al., 2007; Benediktová et al., 2020), and there is no reason why humans should be an exception.

In 1980, Robin Baker claimed that students of the University of Manchester were able to correctly show the direction towards their 'home area' (university campus) after being displaced by car for the distance varying from 6 to $52 \mathrm{~km}$ (Baker, 1980). During displacement, the students were blindfolded and the minibus was driven three times round a roundabout before a particular exit was taken, to make path integration more difficult. In similar experiments performed in Yorkshire, high school students (1617 years old) statistically significantly preferred the correct direction towards their hometown of Barnard Castle. However, only the participants with brass bars fixed at the back of their heads made the correct choice, whereas the participants with magnetic bars of similar size and mass were not able to point to the correct homeward direction (Baker, 1980). These data allowed the author to claim the role of magnetoreception in human homing behavior.

These results, published in Science, and subsequent experiments of the same author (Baker, 1981, 1985) triggered a heated discussion and multiple attempts of independent reproduction (Gould and Able, 1981; Able and Gergits, 1985; Dayton, 1985; Gould, 1985). Summing up, in contrast to claims by Robin Baker (Baker, 1987), the results of his studies of homing in humans (in this case, strictly speaking, the phenomenon studied was not homing, i.e., the ability to actually return to the home area, but rather the ability to point to the homeward direction after displacement) were not replicated either by himself or by fellow researchers (Fildes et al., 1984; Westby and Partridge, 1986; Finney, 1995). To emphasize, it was not the role of magnetic bars (i.e., the potential magnetic sense) that could not be reproduced, but simply the ability of humans to correctly determine homeward direction under controlled conditions. Many anecdotes to this effect are not sufficient: under controlled experimental conditions, the phenomenon was not replicated. The explanations of the discrepancies ranged from pitfalls in the statistical analysis (Dayton, 1985) to careful suggestions of unconscious bias by the researcher and lack of double-blind protocol.

Even if we disregard the problem of non-reproducibility of results, the results raise questions anyway. The author called the behavior he studied 'goal orientation' (Baker, 1981). However, a closer look at the experiments, by Baker and by other authors who tried to reproduce his results, shows that all of them studied the positioning system in humans: the participants were asked not to point to the cardinal directions, but to the direction towards their goal, i.e., where their home range was in respect to their current location. Today this ability is usually called navigation, which is defined as the ability to use the map, or positioning system (Chernetsov, 2016; Mouritsen, 2018). Baker's data suggest a role for magnetoreception in human positioning mechanisms. If we accept these results as valid and reproducible, the most parsimonious explanation for them would be the magnetic map in humans, i.e., use of gradients of the geomagnetic field parameters for positioning in respect to the goal of displacement. However, it should be kept in mind that the scale of displacements of humans, either in Manchester experiments by Robin Baker $(6-52 \mathrm{~km})$ or in Princeton experiments in North America that attempted to replicate Manchester experiments (5-33 km) (Gould, 1985), was at the lower border of the magnetic map resolution, theoretically possible in the best-case scenario (Komolkin et al., 2017). The analysis based on long-term ( $>25$ years) monitoring of the natural fluctuations of the geomagnetic field showed that even if the magnetic field parameters, i.e., total intensity and inclination, are measured by humans or any other animals perfectly accurately (which is certainly impossible), the theoretically achievable spatial resolution of positioning varies from $25-35 \mathrm{~km}$ in some areas and down to $5 \mathrm{~km}$ grain in others, depending on the steepness of magnetic intensity gradient, which varies geographically. If we make a more realistic assumption of field intensity measurement with $0.1 \%$ accuracy (to $c a$. $50 \mathrm{nT}$ ), the accuracy of positioning degrades to $65-80 \mathrm{~km}$ in some areas and $43 \mathrm{~km}$ in others (Komolkin et al., 2017). A putative magnetic map can hardly be useful for spatial navigation at the scale of Baker's experiments. 
In a recent study, participants (20 males aged 1933 years and 21 females aged 19-23 year) were asked to point by hand towards the magnetic North, which may have been rotated in respect to the geographic North by magnetic coils (Chae et al., 2019). Each participant underwent 20 tests in a rotating chair, the results of which were averaged and the mean used in the second-order analysis. The authors reported that food-deprived males, but not females, significantly preferred the magnetic direction that had previously been food-associated. Without food deprivation, neither gender was able to establish such an association (Chae et al., 2019). Gender bias in magnetic orientation the authors cautiously interpret as result of stronger selection for orientation abilities in prehistoric male humans who were dominantly responsible for gathering or hunting for food.

The authors reported that even though the participants pointed towards the magnetic direction with their eyes shut, this ability disappeared if their eyes were additionally covered by black blindfold, or if the participants wore goggles that did not let short-wavelength light in $(<500 \mathrm{~nm})$. The authors interpreted these results as suggesting that human magnetoreception is short-wavelength light dependent and probably based on the magnetochemical features of cryptochrome, as it is widely assumed for one of the avian magnetoreceptory systems (Mouritsen, 2018). The authors believe that light that penetrates the eyelids is sufficient for light-dependent magnetoreception in humans.

These data need independent verification. A detailed inspection of the key result, according to which hungry men can correctly choose the right magnetic direction (which is presented in Fig. 2D, Chae et al., 2019), shows that the statistical significance of the result is based on a single data point, i.e., on a single participant who was very consistent in choosing the right direction. It should also be kept in mind that the authors present the second-order means, i.e., the mean directions shown by each participant in multiple tests. These individual means are presented as dots in circle diagrams, whereas in reality they have broader or narrower confidence intervals that could have been presented as probability bells. It means that a part of variation in experimental data is hidden, and statistical significance is inflated.

Based on the principle that extraordinary claims must be supported by extraordinary robust evidence, we believe that the results of Chae et al. (2019) should be treated as promising and preliminary and need independent verification.

\section{Modulation of vision by geomagnetic field}

In the early 2000s, German researchers performed a series of experiments in which human vision was modulated by the magnetic field (Thoss et al., 2000, 2002; Thoss and Bartsch, 2003). At that time, the radical pair model that attempted to explain visual magnetoreception of birds had already been proposed (Ritz et al., 2000). This model assumes that one of the two magnetoreceptory systems known for this class of animals is vision-based. The primary receptor molecules that make magnetoreception possible are cryptochromes, present in the retinal neurons of birds. It is assumed that cryptochrome molecules localized in photoreceptor cells may be spatially ordered in respect to the surface of the retina. After absorbing short-wavelength photons these molecules produce a chemical response that depends on the direction of the external magnetic field (Hore and Mouritsen, 2016).

The authors claimed that the ability of human participants to sense very dim light stimuli was modulated by the direction of the magnetic field lines in respect to the visual axis (Thoss et al., 2000, 2002; Thoss and Bartsch, 2003). When the directions of view line and field vector coincided, the perception threshold of the light stimulus was slightly but significantly decreased by $4 \%$. The significance was lost if the angle between the directions was set to $20^{\circ}$ (Thoss and Bartsch, 2003). The most obvious effect of the magnetic field on the discrimination sensitivity of light flashes, which threshold approximately twice as low as under control conditions, was observed when the magnetic field was rotated with the period of $110 \mathrm{~s}$ (Thoss et al., 2000). These results are interesting and begging for independent verification, but their theoretical background is not obvious.

Vision-based magnetoreception in birds is believed to result in images formed due to modulation of vision by the static magnetic field (Hore and Mouritsen, 2016; Mouritsen, 2018; Ritz et al., 2000). Thoss et al. claimed to have found modulation of the sensitively threshold for dim light stimulus by the direction of the magnetic field in humans, but they never claimed to have evidence for magnetic-related visual images. Hard evidence for such modulation in humans could facilitate cautious claims of sensory perception of the magnetic field. It remains unclear how humans in their behavior could have used such a sensory mechanism. It is also worth noting that during the nearly two decades since the publication of these results they have not been independently replicated, in spite of the obvious importance of this topic related to human sensory abilities.

\section{EEG analyses}

Apart from behavioral experiments, the results or which we believe cannot be interpreted as supporting the existence of human magnetoreception, this question has been studied by analyzing electroencephalograms (EEG) of participants exposed to Earth-strength magnetic fields. This approach is based on a slightly different angle of view. Obviously, the analysis of EEG cannot 
help to find the morphological substrate of the putative magnetoreception. However, a robust significant response would make it possible to claim that if a sensory signal is processed in the cortical structures of the brain, a system of transduction of this signal into the form accessible to the nervous system must exist (Kulbach and Zavarzina, 2019).

Several research groups tried to answer the question: is the bioelectric activity of the brain modulated by changes in the geomagnetic field? One of the first studies of this topic (Sastre et al., 2002) analyzed spontaneous EEG recorded from participants exposed to the magnetic field with inclination varying from $0^{\circ}$ (value naturally found at the magnetic equator) to $90^{\circ}$ (value found at the magnetic poles), and with the total intensity of the external field up to $90 \mu \mathrm{T}$ (the local field at their study site was $45 \mu \mathrm{T}$ ). Spectral analysis was used to quantify the possible alterations in frequency and/or amplitude of the EEG but showed no significant difference in brain activity under different magnetic conditions. We believe that the analysis of spectral characteristics of spontaneous EEG is not sufficiently sensitive to short-term changes in external stimuli that do not greatly exceed the usual background level of signal, and therefore the results of this study are inconclusive.

A joint U.S.-Japanese research group (Wang et al., 2019) has recently published a most intriguing study. The authors built an experimental setup that allowed them to model and modify Earth-strength magnetic field, with the geomagnetic field shielded. A 64-channel EEG was recorded in the study. Participants were tested in three experimental conditions. In the experimental condition, the magnetic field was either rotated from the first preset orientation to the second, or rotated from the second preset orientation to the first, or left unchanged. In the sham mode, the current flowed antiparallel, without creating a measurable external field, but with the same ohmic and magnetomechanical effects as in the active mode.

The authors took extraordinary precautions to avoid any external stimulation of the nervous system of study participants. The duration of an EEG session was one hour, including multiple 7-min experimental runs. In each run of $>100$ trials, magnetic field direction rotated repeatedly between two preset orientations with field intensity held nearly constant at the ambient lab value. All probes were presented in pseudorandom order, blind for the participants. The experimental chamber was dark, silent, and isolated during the test. Participants sat with their eyes closed in total darkness. They were blind to active versus sham modes, trial sequences, and trial onset timings. Changes in human brain activity were studied using the analysis of event-related synchronization/desynchronization. This method makes it possible to assess the level of activation/deactivation of the cerebral cortex when processing information in a clear temporal relationship with an external stimulus (Pfurtscheller, 2006; Yakovenko et al., 2010). The alpha band was selected, because it dominates activity in the resting state in the absence of a task (Klimesch, 1999). A decrease in the alpha-band power is observed when processing information about external stimuli (Pfurtscheller et al., 1994; Klimesch, 1999; Hartmann et al., 2012). This phenomenon, known as alpha-event-related desynchronization, is widely known in the perception of visual, acoustic and somatosenory cues (Peng et al., 2012), and in the processes of categorization, memory etc. (Ponomarev et al., 2017).

The authors (Wang et al., 2019) reported significant alpha-event-related desynchronization triggered only by horizontal rotations when the static vertical magnetic field was directed downwards, which is typical of the Northern hemisphere. No brain responses were elicited by the same horizontal rotations when the static vertical component was directed upwards (situation found in the areas south of the magnetic equator). This suggests a biological response tuned to the ecology of the local human population, and not a physical effect. Neural response was sensitive to static components of the magnetic field and its polarity. This rules out electrical induction, hardware artifacts including. These results allowed the authors to claim that cortex structures were activated by changes in stationary magnetic field and that 'at least some modern humans transduce changes in Earth-strength magnetic fields into an active neural response. It seems to be a robust result; however, it should be mentioned that fewer than 30 EEG records were included in ANOVA in this study, whereas good signal-tonoise ratio and repeatability of experimental data usually demand analyzing larger datasets (e.g., event-related synchronization/desynchronization in $>80$ participants) (Kropotov et al., 2007; Yakovenko et al., 2010; Ponomarev et al., 2017).

\section{Conclusions}

We believe that several studies stand out among all attempts to find sensory perception of the magnetic field in humans. It concerns, first, the studies by the Thoss group (Thoss et al., 2000, 2002; Thoss and Bartsch, 2003) in which the authors found magnetic modulation of the ability to detect light flashes. These studies seem to be robust and clearly deserve attempts to verify them. It should however be mentioned that modulation of the visual signal by the weak stationary magnetic field should not necessarily occur at the receptor level. It may also happen at higher levels of signal transduction.

The second study that needs attention and replication is the research by Joe Kirschvink's group (Wang et al., 2019). The authors obtained results that indicate cor- 
tical activation with alterations in the stationary magnetic field. This study is methodologically very clean and might be the most convincing evidence available at the moment that modern humans can transduce changes in Earth-strength magnetic fields into neural response, even it is not manifested in their behavior. All attempts to demonstrate behavioral responses to changing magnetic conditions in humans are less than convincing.

From the viewpoint of planning further research (if anyone is interested in this topic), we would like to caution against premature attempts to study the mechanism of putative human magnetoreception. Before trying to disentangle the biophysical and neurobiological basis of this sensory ability, we suggest that its existence is shown beyond reasonable doubt by behavioral and/ or electrophysiological data. Of all vertebrates, the most convincing data is currently available for migrating birds (Wiltschko and Wiltschko, 2019). In these animals, before the focused study of biophysical mechanisms began in earnest (with the theoretical paper by Ritz et al., 2000, capitalizing on earlier work by Schulten et al., 1978, being the milestone), the existence of this sensory modality had been shown in multiple behavioral experiments. Until behavioral and electrophysiological evidence that humans can perceive stationary magnetic field is obtained and repeatedly independently verified by different research groups, any attempts to study the mechanisms of this process will remain too speculative to be constructive. At present, in spite of the aforementioned promising data, we have to admit that no conclusive evidence exists that humans can perceive the Earthstrength stationary magnetic fields.

\section{Acknowledgments}

L. A. Astakhova, to whom the authors are most grateful, made important comments on the draft.

\section{References}

Able, K.P. and Gergits, W. F. 1985. Human navigation. Attempts to replicate Baker's displacement experiment; pp. 569-572 in J. L. Kirschvink, D. S. Jones and B. J. MacFadden (eds.), Magnetite biomineralization and magnetoreception in organisms. A new biomagnetism. Plenum Press, N.Y., London. https://doi.org/10.1007/978-14613-0313-8_28

Baker, R. R. 1980. Goal orientation by blindfolded humans after long-distance displacement: possible involvement of a magnetic sense. Science 210(4469):555-557. https:// doi.org/10.1126/science.7423208

Baker, R. R. 1981. Human navigation and the sixth sense. Hodder and Stoughton, L.

Baker, R. R. 1985. Magnetoreception by man and other primates; pp. 537-561 in J. L. Kirschvink, D.S.Jones and B.J. MacFadden (eds.), Magnetite biomineralization and magnetoreception in organisms. A new biomagnetism. Plenum Press, N. Y., London. https://doi. org/10.1007/978-1-4613-0313-8_26

Baker, R. R. 1987. Human navigation and magnetoreception: the Manchester experiments do replicate. Animal Be- haviour 35(3):691-704. https://doi.org/10.1016/S00033472(87)80105-7

Begall, S., Červený, J., Neef, J., Vojtěch, O., and Burda, H. 2008. Magnetic alignment in grazing and resting cattle and deer. Proceedings of the National Academy of Sciences USA 105(36):13451-13455. https://doi.org/10.1073/ pnas.0803650105

Belopasova, A. V., Kadykov, A. S., Chervyakov, A. V., and Belopasov, V. V. 2015. Diagnostic and therapeutic potential of transcranial magnetic stimulation in aphasic patients. Nevrologicheskiy zhurnal 20(4):23-28. (In Russian)

Benediktová, K., Adámková, J., Svoboda, J., Painter, M.S., Bartoš, L., Nováková, P., Vynikalová, L., Hart, V., Phillips, J., and Burda, H. 2020. Magnetic alignment enhances homing efficiency of hunting dogs. elife 9:e55080. https://doi.org/10.7554/eLife.55080

Bortoletto, M., Veniero, D., Thut, G., and Miniussi, C. 2015. The contribution of TMS-EEG coregistration in the exploration of the human cortical connectome. Neuroscience \& Biobehavioral Reviews 49:114-124. https://doi. org/10.1016/j.neubiorev.2014.12.014

Chae, K.-S., Oh, I.-T., Lee, S.-H., and Kim, S.-C. 2019. Blue lightdependent human magnetoreception in geomagnetic food orientation. PLOS ONE 14(2):e0211826. https://doi. org/10.1371/journal.pone.0211826

Charnukha, T.N., Likhachev, S.A., Hleb, V.U., and Zabrodzets, G.V. 2016. The evaluation of safety and adverse effects of transcranial magnetic stimulation in patients with muscular dystonia. Doklady BGUIR 7(101):371-373. (In Russian)

Chernetsov, N.S. 2016. Orientation and navigation of migrating birds. Biology Bulletin 43(8):788-803. https://doi. org/10.1134/S1062359016080069

Chervyakov, A. V., Poydasheva, A. G., Nazarova, M. A., Gnezditsky, V. V., Suponeva, N. A., Chernikova, L. A., and Piradov, M. A. 2015. Navigated repetitive transcranial magnetic stimulation in post-stroke rehabilitation: a randomized, double-blind, sham-controlled study. Annaly klinicheskoy $i$ eskprimentalnoy nevrologii 9(4):30-36. (In Russian)

Dayton, T. 1985. Statistical and methodological critique of Baker's chapter; pp. 563-568 in J. L. Kirschvink, D. S. Jones and B. J. MacFadden (eds.), Magnetite biomineralization and magnetoreception in organisms. A new biomagnetism. Plenum Press, N. Y., London. https://doi. org/10.1007/978-1-4613-0313-8_27

Deutschlander, M. E., Freake, M. J., Borland, S. C., Phillips, J. B., Madden, R. C., Anderson, L. E., and Wilson, B. W. 2003. Learned magnetic compass orientation by the Siberian hamster, Phodopus sungorus. Animal Behaviour 65(4):779-786. https://doi.org/10.1006/anbe.2003.2111

Dolnik, V. R. 1973. Astronomic orientation of birds; pp. 1461 in Orientation of birds and territorial links of avian populations. Zinatne, Riga. (In Russian)

Emlen, S. T., Wiltschko, W., Demong, N. J., Wiltschko, R., and Bergman, S. 1976. Magnetic direction finding: evidence for its use in migratory indigo buntings. Science 193(4252):505508. https://doi.org/10.1126/science.193.4252.505

Evstigneev, V.V. and Kisten', O. V. 2013. Transcranial magnetic stimulation in complex therapy of epilepsy. Annaly klinicheskoy $i$ eskprimentalnoy nevrologii 7(2):20-26. (In Russian)

Fildes, B. N., O'Loughlin, B. J., Bradshaw, J. L., and Ewens, W. J. 1984. Human orientation with restricted sensory information: no evidence for magnetic sensitivity. Perception 13:229-236. https://doi.org/10.1068/p130229

Finney, B. A. 1995. Role for magnetoreception in human navigation? Current Anthropology 36(3):500-506. https://doi. org/10.1086/204386 
Gippenreyter, Yu. B., Lyubimov, V. V., and Mikhalevskaya, M. B. (eds.) 2002. Psychology of sensations and perception. 2nd ed. CheRo, MPSI Publ., Moscow. (In Russian)

Gould, J. L. 1985. Absence of human homing ability as measured by displacement experiments; pp. 595-599 in J. L. Kirschvink, D.S. Jones and B.J.MacFadden (eds.), Magnetite biomineralization and magnetoreception in organisms. A new biomagnetism. Plenum Press, N. Y., London. https://doi.org/10.1007/978-1-4613-0313-8_30

Gould, J. L. and Able, K.P. 1981. Human homing: an elusive phenomenon. Science 212(4498):1061-1063. https://doi. org/10.1126/science.7233200

Hartmann, T., Schlee, W., and Weisz, N. 2012. It's only in your head: expectancy of aversive auditory stimulation modulates stimulus-induced auditory cortical alpha desynchronization. Neuroimage 60:170-178. https://doi. org/10.1016/j.neuroimage.2011.12.034

Heyers, D., Zapka, M., Hoffmeister, M., Wild, J. M., and Mouritsen, H. 2010. Magnetic field changes activate the trigeminal brainstem complex in a migratory bird. Proceedings of the National Academy of Sciences USA 107(20):93949399. https://doi.org/10.1073/pnas.0907068107

Hoffman, R. E., Boutros, N. N., Hu, S., Berman, R. M., Krystal, J.H., and Charney, D.S. 2000. Transcranial magnetic stimulation and auditory hallucinations in schizophrenia. The Lancet 355(9209):1073-1075. https://doi. org/10.1016/S0140-6736(00)02043-2

Holland, R., Thorup, K., Vonhof, M. J., Cochran, W. W., and Wikelski, M. 2006. Bat orientation using Earth's magnetic field. Nature 444(7120):702. https://doi.org/10.1038/444702a

Hore, P.J. and Mouritsen, H. 2016. The radical-pair mechanism of magnetoreception. Annual Review of Biophysics 45:299-344. https://doi.org/10.1146/annurev-biophys-032116-094545

Huerat, P. and Volpe, T. 2009. Transcranial magnetic stimulation, synaptic plasticity and network oscillations. Journal of NeuroEngineering and Rehabilitation 6:7. https://doi. org/10.1186/1743-0003-6-7

Klimesch, W. 1999. EEG alpha and theta oscillations reflect cognitive and memory performance: a review and analysis. Brain Research Review 29(2-3):169-195. https://doi. org/10.1016/s0165-0173(98)00056-3

Kobylkov, D., Schwarze, S., Michalik, B., Winklhofer, M., Mouritsen, H., and Heyers, D. 2020. A newly identified trigeminal brain pathway in a night-migratory bird could be dedicated to transmitting magnetic map information. Proceedings of the Royal Society B 287:20192788. https:// doi.org/10.1098/rspb.2019.2788

Komolkin, A. V., Kupriyanov, P., Chudin, A., Bojarinova, J., Kavokin, K., and Chernetsov, N. 2017. Theoretically possible spatial accuracy of geomagnetic maps used by migrating animals. Journal of Royal Society Interface 14(128):20161002. https://doi.org/10.1098/rsif.2016.1002

Kropotov, J. D., Grin-Yatsenko, V. A., Ponomarev, V. A., Chutko, L. S., Yakovenko, E. A., and Nikishena, I. S. 2007. Changes in EEG spectrograms, event-related potentials and event-related desynchronization induced by relative beta training in ADHD children. Journal of Neurotherapy 11(2):3-11. https://doi.org/10.1300/J184v11n02_02

Kulbach, O.S. and Zavarzina, N. Yu. 2019. Sensory systems: anatomy and physiology. SPbGPMU, St. Petersburg. (In Russian)

Malewski, S., Begall, S., and Burda, H. 2018. Learned and spontaneous magnetosensitive behaviour in the Roborovski hamster (Phodopus roborovskii). Ethology 28(6):423-431. https://doi.org/10.1111/eth.12744

Middendorff, A.T.von. 1855. Die Isepiptesen Russlands. Grundlagen zur Erforschung der Zugzeiten und Zugrich- tungen der Vögel Russlands. Memoires de Academie de Sciences de St. Petersbourg. Serie VI. 8:1-143.

Misra, U. K., Kalita, J., Tripathi, G., and Bhoi, S. K. 2017. Role of $\beta$-endorphin in pain relief following high rate repetitive transcranial magnetic stimulation in migraine. Brain Stimulation 10(3):618-623. https://doi.org/10.1016/j. brs.2017.02.006

Mouritsen, H. 2018. Long-distance navigation and magnetoreception in migratory animals. Nature 558(7708):50-59. https://doi.org/10.1038/s41586-018-0176-1

Norrsell, U., Finger, S., and Lajonchere, C. 1999. Cutaneous sensory spots and the "law of specific nerve energies": history and development of ideas. Brain Research Bulletin 48 (5):457-465. https://doi.org/10.1016/S03619230(98)00067-7

Pakhomov, A., Anashina, A., Heyers, D., Kobylkov, D., Mouritsen, H., and Chernetsov, N. 2018. Magnetic map navigation in a migratory songbird requires trigeminal input. Scientific Reports 8:11975. https://doi.org/10.1038/ s41598-018-30477-8

Phillips, J.B., Youmans, P.W., Muheim, R., Sloan, K. A., Landler, L., Painter, M. S., and Anderson, C. R. 2013. Rapid learning of magnetic compass direction by C57BL/6 mice in a 4-armed 'plus' water maze. PLOS ONE 8(8):e73112. https://doi.org/10.1371/journal.pone.0073112

Peng, W., Hu, L., Zhang, Z., and Hu, Y. 2012. Causality in the association between P300 and alpha event-related desynchronization. PLOS ONE 7(4):e34163. https://doi. org/10.1371/journal.pone.0034163

Perera, T., George, M. S., Grammer, G., Janicack, P. G., Pascual-Leone, A., and Wirecki, T.S. 2016. The clinical TMS society consensus review and treatment recommendation for TMS therapy for major depressive disorder. Brain Stimulation 9(3):336-346. https://doi.org/10.1016/j. brs.2016.03.010

Pfurtscheller, G. 2006. The cortical activation model (CAM). Progress in Brain Research 159:19-27. https://doi. org/10.1016/S0079-6123(06)59002-8

Pfurtscheller, G., Neuper, C., and Mohl, W. 1994. Event-related desynchronization (ERD) during visual processing. International Journal of Psychophysiology 16:147-153. https:// doi.org/10.1016/0167-8760(89)90041-X

Ponomarev, V.A., Pronina, M.V., and Kropotov, Yu.D. 2017. Dynamics of the EEG spectral density in the $\theta, a$, and $\beta$ bands in the visual Go/NoGo task. Human Physiology 43(4):366-376. https://doi.org/10.1134/ S0362119717040132

Ritz, T., Adem, S., and Schulten, K. 2000. A model for photoreceptor-based magnetoreception in birds. Biophysical Journal 78(2):707-718. https://doi.org/10.1016/S00063495(00)76629-X

Rüppel, W. 1944. Versuche über Heimfinden ziehender Nebelkrähen nach Verfrachtung. Journal für Ornithologie 92:106-132. https://doi.org/10.1007/BF02086330

Sastre, A., Graham, C., Cook, M. R., Gerkovich, M. M., and Gailey, P. 2002. Human EEG responses to controlled alterations of the Earth's magnetic field. Clinical Neurophysiology 113:1382-1390. https://doi.org/10.1016/s13882457(02)00186-4

Schlaepfer, T.E. and Kosel, M. 2004. Transcranial magnetic stimulation in depression; pp. 1-22 in S. H. Lisanby (ed.), Review of Psychiatry Series, Vol. 23 no. 1. Brain stimulation in psychiatric treatment. American Psychiatric Publishing, Inc.

Schmidt, R. F. (ed.) 1981. Fundamentals of sensory physiology. 2nd ed. Springer, N. Y., Heidelberg, Berlin.

Schulten, K., Swenberg, C.E., and Weller, A. 1978. A biomagnetic sensory mechanism based on magnetic field 
modulated coherent electron spin motion. Zeitschrift für Physikalische Chemie (NF) 111(1):1-5. https://doi. org/10.1524/zpch.1978.111.1.001

Skiles, D. D. 1985. The geomagnetic field. Its nature, history, and biological relevance; pp. 43-102 in J. L. Kirschvink, D. S. Jones and B. J. MacFadden (eds.), Magnetite biomineralization and magnetoreception in organisms. A new biomagnetism. Plenum Press, N. Y., London. https://doi. org/10.1007/978-1-4613-0313-8_3

Thorup, K., Bisson, I., Bowlin, M., Holland, R., Wingfield, J., Ramenofsky, M., and Wikelski, M. 2007. Evidence for a navigational map stretching across the continental U.S. in a migratory songbird. Proceedings of the National Academy of Sciences USA 104:18115-18119. https://doi. org/10.1073/pnas.0704734104

Thoss, F. and Bartsch, B. 2003. The human visual threshold depends on direction and strength of a weak magnetic field. Journal of Comparative Physiology A 189(10):777779. https://doi.org/10.1007/s00359-003-0450-y

Thoss, F., Bartsch, B., Fritzsche, B., Tellschaft, D., and Thoss, M. 2000. The magnetic field sensitivity of the human visual system shows resonance and compass characteristic. Journal of Comparative Physiology A 186(10):1007-1010. https://doi.org/10.1007/s003590000166

Thoss, F., Bartsch, B., Tellschaft, D., and Thoss, M. 2002. The light sensitivity of the human visual system depends on the direction of view. Journal of Comparative Physiology
A 188(3):235-237. https://doi.org/10.1007/s00359-0020300-3

Wang, C. X., Hilburn, I. A., Wu, D.-A., Mizuhara, Y., Cousté, C. P., Abrahams, J. N. H., Bernstein, S. E., Matani, A., Shimojo, S., and Kirschvink, J. L. 2019. Transduction of the geomagnetic field as evidenced from alpha-band activity in the human brain. eNeuro 6(2):e0483-18.2019. https:// doi.org/10.1523/ENEURO. 0483-18.2019

Westby, G. W. and Partridge, K. J. 1986. Human homing: still no evidence despite geomagnetic controls. Journal of Experimental Biology 120:325-331.

Wiltschko, R. and Wiltschko, W. 2019. Magnetoreception in birds. Journal of Royal Society Interface 16:20190295. https://doi.org/10.1098/rsif.2019.0295

Wiltschko, W. 1968. Über den Einfluß statischer Magnetfelder auf die Zugorientierung der Rotkehlchen (Erithacus rubecula). Zeitschrift der Tierpsychologie 25(5):537-558. https://doi.org/10.1111/j.1439-0310.1968.tb00028.x

Wiltschko, W. and Wiltschko, R. 1972. Magnetic compass of European robins. Science 176(4030):62-64. https://doi. org/10.1126/science.176.4030.62

Yakovenko, E. A., Nikishena, I. S., Ponomarev, V. A., and Kropotov, Ju. D. 2010. Correlation between EEG event-related synchronization in theta band and degree of attention disorder in children with ADHD in test GO/NOGO. Ekologiya cheloveka 11:9-18. (In Russian) 